\title{
Caracterização de iniciativas de geração de trabalho e renda destinadas a usuários de serviços de saúde mental e aproximação com a economia solidária: a realidade do Estado de São Paulo
}

\section{Characterization of work and income generation initiatives for users of mental health services and its connection to the solidarity economy: the reality in São Paulo State}

\author{
Giovana Garcia Morato ${ }^{1}$, Isabela Aparecida de Oliveira Lussi ${ }^{2}$
}

http://dx.doi.org/10.11606/issn.2238-6149.v26i3p336-344

\begin{abstract}
Morato GG, Lussi IAO. Caracterização de iniciativas de geração de trabalho e renda destinadas a usuários de serviços de saúde mental e aproximação com a economia solidária: a realidade do Estado de São Paulo. Rev Ter Ocup Univ São Paulo. 2015 set.dez.;26(3):336-44.

RESUMO: A inauguração da parceria entre a Área Técnica de Saúde Mental e a Secretaria Nacional de Economia Solidária com o objetivo de fomentar as iniciativas de trabalho no campo da saúde mental, impulsionou o aumento progressivo no número destas inciativas e o investimento nestas como estratégias de inclusão social. O presente estudo teve como objetivos caracterizar as iniciativas de geração de trabalho e renda compostas por usuários de serviços de saúde mental no estado de São Paulo e identificar se estas iniciativas estão vinculadas ao movimento da economia solidária. Trata-se de um estudo transversal descritivo de abordagem qualitativa do qual participaram 16 terapeutas ocupacionais. Para a coleta de dados foi elaborado um questionário semiestruturado. Os dados provenientes deste instrumento foram analisados de maneira descritiva. Os resultados revelam que o tempo de existência das iniciativas variou entre 5 e 20 anos, que a maioria conta somente com usuários da saúde mental e afirmam estar vinculadas à economia solidária. O presente estudo revelou aspectos potenciais das iniciativas no processo de afirmação dos usuários como cidadãos e potenciais trabalhadores, entretanto, desafios precisam ser enfrentados, principalmente no que diz respeito à geração de renda.
\end{abstract}

DESCRITORES: Reabilitação; Saúde mental; Trabalho; Ação intersetorial.

\begin{abstract}
Morato GG, Lussi IAO. Characterization of work and income generation initiatives for users of mental health services and its connection to the solidarity economy: the reality in São Paulo State. Rev Ter Ocup Univ São Paulo. 2015 Sept.Dec.;26(3):336-44.

ABSTRACT: The inauguration of the partnership between the technical area of mental healthcare and the National Secretary of Solidary Economy to foster work initiatives in the context of mental healthcare led to their progressive increase and brought more investments for them, as part of a strategy focused on social inclusion. This study characterizes initiatives aimed at work and income generation for users of mental health services in the state of São Paulo and examines if they are linked to solidarity economy. Sixteen occupational therapists participated in this cross-sectional descriptive study with a qualitative approach, and we developed a semi-structured questionnaire to collect data, which were analyzed descriptively. Results showed that initiatives had existed for 5 to 20 years, and most of them relied only on mental healthcare users and claimed to be related to solidarity economy. This study revealed the potential aspects of the initiatives in the affirmation process of the users as citizens and workers; however, challenges need to be faced, especially regarding income generation.
\end{abstract}

KEYWORDS: Rehabilitation; Mental health; Work; Intersectoral action.

Este artigo é oriundo da dissertação de mestrado defendida pela primeira autora junto ao Programa de Pós-Graduação em Terapia Ocupacional da UFSCar, apoio financeiro da Coordenação de Aperfeiçoamento de Pessoal de Nível Superior (CAPES).

1. Professora Assistente da Universidade Federal de São Carlos - UFSCar, Departamento de Terapia Ocupacional da Universidade Federal de São Carlos - UFSCar. Doutoranda no Programa de Pós-Graduação em Terapia Ocupacional da Universidade Federal de São Carlos - UFSCar. E-mail: giovana_morato@hotmail.com.

2. Professora Adjunta da Universidade Federal de São Carlos - UFSCar, Departamento de Terapia Ocupacional, Programa de Pós-Graduação em Terapia Ocupacional, Núcleo Multidisciplinar e Integrado de Estudos, Formação e Intervenção em Economia Solidária (NuMI-EcoSol) de São Carlos-UFSCar. Bolsista do CNPq - Brasil. E-mail: bellussi@ufscar.br.

Endereço para correspondência: Universidade Federal de São Carlos - Departamento de Terapia Ocupacional. Rodovia Washington Luiz, Km 235, SP - 310, CEP: 13565-905. São Carlos, São Paulo, Brasil. E-mail: giovana_morato@hotmail.com. 


\section{INTRODUÇÃO}

$\mathrm{O}$ modelo de assistência em Saúde Mental vem se reconfigurando, no Brasil, desde a eclosão do movimento da Reforma Psiquiátrica, iniciado no final da década de $1970^{1}$. Compreendida como um importante movimento de inclusão social, a Reforma Psiquiátrica implica, mais do que a substituição de hospitais psiquiátricos por um modelo de assistência comunitário mais humanizado e moderno, na mudança dos conceitos e da concepção social acerca da loucura, bem como na construção de um novo lugar social para os sujeitos com transtorno mental ${ }^{2}$.

Em meio às transformações ocorridas na assistência em saúde mental norteadas pelos princípios e valores difundidos pelo movimento da Reforma Psiquiátrica, surge a discussão acerca da importância do trabalho como uma das formas de promover a inclusão social das pessoas com transtorno mental. Nesse sentido, a partir da década de 1990 começam a despontar as primeiras iniciativas de geração de trabalho e renda no âmbito da saúde mental no Brasil ${ }^{3}$.

Foi também no decorrer do desenvolvimento da proposta de inclusão social pelo trabalho que o movimento da economia solidária se colocou como parceiro da área de saúde mental na proposição de trabalhos inclusivos para a população excluída socialmente ${ }^{4}$. Isso se deve, principalmente, porque "os movimentos da Reforma Psiquiátrica e da Economia Solidária compartilham princípios fundamentais quando fazem a opção ética, política e ideológica por uma sociedade marcada pela solidariedade" (p.37) ${ }^{1}$.

Nesse sentido, em 2004 a realização da primeira Oficina de Experiências de Geração de Renda e Trabalho de Usuários de Serviços de Saúde Mental promovida por meio da parceria entre os Ministérios da Saúde e do Trabalho e Emprego, permitiu o primeiro contato com experiências de geração de trabalho e renda existentes em todo o país e produziu o alicerce para o estabelecimento de um produtivo diálogo entre as políticas de saúde mental e economia solidária ${ }^{1}$. Portanto, a realização deste evento inaugurou a parceria entre a Área Técnica de Saúde Mental do Ministério da Saúde e a Secretaria Nacional de Economia Solidária do Ministério do Trabalho e Emprego com o objetivo de fomentar as iniciativas de geração de trabalho e renda no âmbito da saúde mental ${ }^{5}$.

Saraceno ${ }^{6}$ considera o trabalho como um dos eixos fundamentais implicados no processo de reabilitação das pessoas com transtorno mental. Para o autor, a reabilitação diz respeito a "um processo de reconstrução, um exercício pleno da cidadania, e, também, de plena contratualidade nos três grandes cenários: habitat, rede social e trabalho com valor social" (p.16) ${ }^{6}$. Para Carvalhaes ${ }^{7}$, considerar a reabilitação psicossocial que de fato aconteça é vislumbrar condições que garantam possibilidades de alcance de autonomia e protagonismo pelos usuários por meio do trabalho.

Segundo Andrade et al. ${ }^{8}$ a Rede Brasileira de Saúde Mental e Economia Solidária e o Cadastro de Iniciativas de Inclusão Social pelo Trabalho (CIST) são os dispositivos institucionais da Política Nacional Intersetorial de Saúde Mental e Economia Solidária. Nesse sentido, uma das recomendações feitas pelo Grupo de Trabalho Interministerial ao Ministério da Saúde foi que este órgão mantivesse o CIST atualizado a fim de torná-lo um banco de dados digital com livre acesso para a realização de atualizações, cadastramentos e visualização dos dados disponibilizados ${ }^{9}$, evidenciando a importância desse dispositivo como meio de mapear as iniciativas existentes, estabelecer diálogos com estas e fomentar a elaboração e implementação de políticas públicas.

Dentre as informações disponibilizadas no documento Saúde Mental em Dados é possível verificar que em maio de 2006 já havia 230 experiências de geração de trabalho e renda mapeadas por meio do $\mathrm{CIST}^{10}$. A versão mais recente deste documento aponta que o número de experiências mapeadas entre 2005 e 2012 já chegou a $660^{11}$ evidenciando um crescente uso destas experiências como propulsoras do processo de inclusão social.

Diante do exposto, e considerando a importância de se pautar o trabalho no âmbito da saúde mental como um direito e como meio efetivo de inclusão social e conquista da cidadania, é que o presente estudo teve como objetivos caracterizar as iniciativas de geração de trabalho e renda compostas por usuários da saúde mental no estado de São Paulo cadastradas no CIST e identificar se estas iniciativas estão vinculadas ao movimento da economia solidária.

\section{METODOLOGIA}

Trata-se de um estudo transversal descritivo de abordagem qualitativa.

Ressalta-se que os resultados apresentados representam um recorte de uma pesquisa maior, cujo objetivo geral foi investigar a prática dos terapeutas ocupacionais que trabalham em iniciativas de geração de trabalho e renda no estado de São Paulo, cadastradas no CIST.

\section{Participantes}

Participaram da pesquisa 16 terapeutas 
ocupacionais, em sua totalidade do sexo feminino, com idade variando entre 27 e 50 anos. Todas as participantes se formaram no estado de São Paulo, com tempo de formação profissional variando entre quatro e 27 anos.

\section{Campo do estudo}

O campo de estudo foi composto por 10 iniciativas de geração de trabalho e renda distribuídas em cinco cidades do estado de São Paulo. Foram selecionadas para participar da pesquisa as iniciativas que, além de estarem cadastradas no CIST, estavam ativas e tinham o terapeuta ocupacional com vínculo formal atuando no serviço, uma vez que, como apontado anteriormente, o objetivo geral do estudo era investigar a prática deste profissional nas iniciativas.

\section{Instrumento}

Para a realização da coleta de dados foi elaborado um questionário semiestruturado a partir da revisão da literatura e baseado nos objetivos estabelecidos na pesquisa. Teve como finalidade caracterizar as iniciativas de geração de trabalho e renda por meio de informações como tempo de existência da iniciativa, produtos por ela gerados, composição da população participante, renda mensal gerada entre outros. Para tanto, parte de sua construção foi baseada no conteúdo do formulário CIST, compreendendo que tais conteúdos poderiam subsidiar as informações pretendidas de maneira consistente.

\section{Procedimentos}

Inicialmente o projeto de pesquisa foi submetido a um Comitê de Ética em Pesquisa em Seres Humanos, tendo sido aprovado sob o Número de Parecer 137.628./ CAAE: 05460812.9.0000.5504. Somente após a aprovação deu-se início à coleta de dados.

A identificação das iniciativas de geração de trabalho e renda foi feita por meio de consulta ao banco de dados de iniciativas de geração de renda disponível na página eletrônica do Ministério da Saúde no campo de informações relativas à Saúde Mental, no qual constavam 99 iniciativas no estado de São Paulo. As informações disponíveis no documento consultado são referentes ao CIST, um formulário eletrônico no qual as iniciativas de geração de trabalho e renda podem ser cadastradas.

O contato com as 99 iniciativas foi feito inicialmente por telefone, considerando esta via a mais efetiva para a obtenção de informações.

Para os locais nos quais não estava disponível o número telefônico no banco de dados, ou nos casos em que não se conseguiu concluir a ligação, lançou-se mão de envio de mensagem por meio de correio eletrônico.

Dos 99 locais que abrigam as iniciativas foram contatados 97, pois dois deles não disponibilizaram contato telefônico e nem endereço de e-mail no banco de dados.

Após contato com as iniciativas, identificou-se que somente 14 respondiam aos critérios para participar do estudo. Assim, foi solicitada autorização por escrito aos responsáveis por estas para a realização da pesquisa e, em seguida, foi feito o convite às participantes por meio de contato telefônico e mensagem de e-mail explicando os objetivos da pesquisa e esclarecendo sobre os aspectos éticos.

Às profissionais que aceitaram participar da pesquisa, foi solicitado que assinassem o Termo de Consentimento Livre e Esclarecido (TCLE). Para aquelas que assinaram o TCLE, foi enviado o questionário semiestruturado via correio eletrônico, em formato Word o qual deveria ser respondido no próprio documento e encaminhado à pesquisadora via correio eletrônico.

Finalizado o prazo para o preenchimento do questionário, foram respondidos 18 dos 23 enviados. Entretanto, após minuciosa análise, dois deles foram excluídos por identificarem as iniciativas como oficinas terapêuticas e não como propostas de trabalho e renda.

Portanto, o número final de participantes foi $16 \mathrm{e}$ o número de iniciativas participantes foi 10 distribuídas em cinco cidades do estado de São Paulo.

\section{Análise dos dados}

A análise dos questionários se deu de forma descritiva, sendo realizada a partir da ordenação e numeração dos questionários na ordem de seu retorno. Os dados provenientes deste instrumento foram organizados sequencialmente segundo as perguntas respondidas e seu conteúdo subsidiou a caracterização dos sujeitos, bem como a caracterização das iniciativas de geração de trabalho e renda.

\section{RESULTADOS E DISCUSSÃO}

A partir da análise minuciosa dos questionários foi possível identificar que das 10 iniciativas participantes do estudo, cinco se tratam de um único grupo de produção e cinco se tratam de serviços de geração de trabalho e renda nos quais se desenvolvem vários grupos de produção.

O tempo de existência destas iniciativas variou 
entre cinco e 20 anos, de forma que a maioria existe há mais de cinco anos.

Quanto ao número de participantes por iniciativa, destaca-se que nas que se referem a um único grupo de produção este número variou entre três e 10 pessoas, enquanto que nas iniciativas que se tratam de serviços de geração de trabalho e renda este número, quando informado, variou entre 42 e 96 pessoas distribuídas entre os vários grupos de produção desenvolvidos nos serviços.

Estes dados revelam que o número de participantes é relativamente baixo frente à demanda que existe atualmente visto que, como apontado no Relatório Final do Grupo de Trabalho Saúde Mental e Economia Solidária, a iniciativa da Coordenação Nacional de Saúde Mental em iniciar, em 2004, o mapeamento das iniciativas a fim de desenvolver uma política de Inclusão Social pelo trabalho exequível, foi estimulada justamente pela recorrente demanda proveniente dos movimentos de usuários de serviços de saúde mental, trabalhadores e familiares ${ }^{9}$.

Nesse sentido, questiona-se os motivos da baixa quantidade de usuários nas iniciativas, e se esta é uma realidade específica destas ou se existem outras nesta mesma condição, haja vista que existe demanda real por esta modalidade de trabalho, como apontado no Relatório Final supracitado, e ainda, que os dados disponibilizados no documento Saúde Mental em Dados em suas várias versões evidenciam um aumento crescente destas iniciativas no âmbito nacional.

Argumenta-se que é fundamental a efetiva participação dos usuários nas iniciativas, pois somente assim é possível identificar necessidade de melhorias, aprimoramentos e políticas públicas, principalmente no que diz respeito à maior sustentabilidade destas já que, como afirma Delgado ${ }^{12}$, estas "mostram em sua diversidade duas características comuns: a angústia por serem frágeis e com pouca sustentação institucional e financeira, e a certeza dos bons resultados obtidos e da adesão dos usuários" (p.9) ${ }^{12}$.

No que se refere ao número de participantes em iniciativas de trabalho, o estudo desenvolvido por Tagliaferro $^{13}$ revelou que para alguns profissionais que compõem uma equipe de incubação de um empreendimento solidário da saúde mental, o número de usuários que participava do empreendimento estava diminuindo, além de haver aqueles que não decidiam se iriam permanecer no grupo ou não. Ainda, o estudo desenvolvido por Milioni ${ }^{14}$, ao apreender a experiência dos usuários integrantes deste mesmo empreendimento solidário, revelou que este ainda não gerava renda satisfatória. A autora considera que a baixa renda gerada pode desestimular alguns usuários participantes do empreendimento ou ainda ser uma barreira para a entrada de novos integrantes ${ }^{14}$.

Os dados apontados pelos estudos supracitados podem contribuir na investigação e hipóteses quanto ao número relativamente baixo de usuários encontrados nas iniciativas estudadas, principalmente no que se refere à baixa renda gerada, entretanto, certamente não se limitam a estes.

O estudo revelou que a maioria das iniciativas estudadas conta somente com usuários da saúde mental no grupo de trabalhadores. Sobre esta condição comumente encontrada, Singer ${ }^{15}$ aponta que é importante que as cooperativas e associações não sejam compostas exclusivamente por pessoas com transtornos mentais, mas que agreguem outras populações, visto que quando os acometimentos são distintos eles se complementam e contribuem bastante para que haja um campo de manifestação maior.

Delgado $^{16}$, ao acolher as sugestões feitas por Singer ${ }^{15}$ sobre a importância de os empreendimentos serem heterogêneos, pondera sobre a necessidade de a Rede de Saúde Mental e Economia Solidária ser ampliada para outras parcelas excluídas da sociedade, e não ser composta exclusivamente por pessoas com transtorno mental.

Segundo Ghirardi ${ }^{17}$, a cooperativa inclusiva ou mista diz respeito a uma cooperativa que congrega pessoas sob várias condições, ou seja, pessoas há tempos desempregadas e pessoas com variados acometimentos físicos e psíquicos que apresentam histórico de afastamento do trabalho.

Nesse contexto é possível apresentar, como possibilidade viável para se alcançar uma proposta de trabalho com maior potencial, o modelo de cooperativa integrada bastante difundido na experiência italiana, a qual, do ponto de vista jurídico

(...) é caracterizada pela presença de sócios "normais" e sócios "inabilitados" (na proporção de pelo menos $40 \%$ ), e da sustentação das entidades locais (sobretudo as regionais), o que se concretiza em intervenções promocionais (facilidades para equipamentos e locais); facilidade na inserção dos desabilitados (fiscalização dos ônus sociais); intervenções para favorecer a produção (linhas de crédito facilitado e cursos de formação) $(\mathrm{p} .134)^{18}$.

Tais cooperativas são denominadas de cooperativas sociais e são importantes dispositivos de reabilitação psicossocial de usuários da saúde mental no contexto italiano. Inspirado neste modelo, o movimento de Reforma Psiquiátrica brasileira tem investido esforços no sentido de 
tornar o cooperativismo social uma realidade no cenário nacional.

Com a consolidação da Política Nacional de Saúde Mental e Economia Solidária o movimento do cooperativismo social ganhou força e recentemente foi aprovado o Decreto $N^{\circ} 8.163$, que institui o Programa Nacional de Apoio ao Associativismo e Cooperativismo Social denominado Pronacoop Social ${ }^{19}$, que tem a finalidade de fomentar o desenvolvimento das cooperativas sociais e dos empreendimentos econômicos solidários sociais. Observa-se que este é um importante passo na direção da implantação de grupos mistos.

Quanto à frequência com que os grupos desenvolvem suas atividades de trabalho, nas iniciativas que se tratam de um único grupo de produção verificou-se que apenas duas desenvolvem suas atividades de segunda à sexta-feira, as demais, no máximo duas vezes na semana, ao contrário dos serviços de geração de trabalho e renda que, em quase sua totalidade, desenvolvem suas atividades de segunda à sexta-feira.

Essa condição remete à discussão acerca da importância de se propor um trabalho que, dentre outros aspectos, deve ser realizado em um período condizente a uma jornada que permita uma organização da produção e comercialização compatíveis com as exigências para que possa entrar no mercado. Ressalta-se, entretanto, que a proposta não é enquadrar as iniciativas no modelo capitalista, até porque, como será discutido posteriormente, estas são desenvolvidas pautadas nos princípios da economia solidária, mas encontrar meios para que, seguindo os princípios desta economia, seja possível balizar o funcionamento da iniciativa à sua entrada no circuito da venda e comercialização.

Ainda, pensar o tempo de funcionamento das iniciativas e sua consequente entrada no mercado de trabalho contribui para a desconstrução de uma possível percepção de que estas são sinônimo de oficinas tais como as que são desenvolvidas nos Centros de Atenção Psicossocial (CAPS), por exemplo. Esta distinção é fundamental para que a proposta de geração de trabalho e renda cinda por completo com a perspectiva das oficinas terapêuticas e assim avance na proposta de, gerando trabalho e renda, viabilizar o acesso dos usuários ao mundo das trocas materiais, afetivas e sociais.

No que se refere à forma de funcionamento das iniciativas apontadas pelas participantes temse: empreendimento econômico solidário, grupo de produção, oficina de geração de renda, cooperativa social e associação. Chama atenção as várias denominações dadas, principalmente pela constatação neste estudo de que, nos serviços que desenvolvem vários grupos de produção, as participantes de um mesmo serviço deram denominações diferentes para os grupos que acompanham. Esperava-se que, nesta condição, as participantes dessem a mesma denominação, visto que por se tratar de um serviço que abriga vários grupos de produção estas adotassem uma única forma de funcionamento.

Este dado pode revelar falta de compreensão e mesmo de consenso acerca do que efetivamente se referem estas formas de funcionamento. Nessa direção, Andrade et al. ${ }^{8}$ apontam que atualmente existem duas formas de denominar as iniciativas sendo elas: iniciativas de geração de trabalho e renda, adotada pela Rede Brasileira de Saúde Mental e Economia Solidária, e iniciativas de inclusão social pelo trabalho, adotada no CIST, além de denominações tais como empreendimentos de saúde mental e economia solidária e cooperativas sociais. Para as autoras, talvez essa diversidade de denominações revele a atual condição de construção da política de inclusão social pelo trabalho e sua particularidade quanto à realidade social em que é desenvolvida.

Os apontamentos feitos pelas autoras supracitadas talvez possa respaldar e, em partes, justificar a condição encontrada neste estudo acerca das várias denominações apresentadas.

No que se refere às atividades de produção/serviço desenvolvidas nas iniciativas, foi possível constatar que a maioria investe em atividades de produção e que estes produtos, em geral, estão fortemente ligadas ao ramo artesanal, sendo que somente três, das 10 iniciativas investem em prestação de serviços. $\mathrm{O}$ estudo desenvolvido por Gigante ${ }^{20}$, realizado no contexto de iniciativas de geração de trabalho e renda no âmbito da saúde mental, também evidenciou uma tendência na escolha por atividades artesanais e oferta de produtos em detrimento da prestação de serviços.

É fundamental a discussão acerca da escolha da atividade produtiva, bem como da diversificação do que é produzido. Ou seja, existiu uma tradição na psiquiatria quanto ao uso de atividades artesanais nos hospitais psiquiátricos que se prestavam, dentre outras, à ocupação do tempo ocioso dos internos respaldado pela perspectiva terapêutica. Nesse sentido, aponta-se a necessidade de repensar o tipo de atividade produtiva como forma de desmistificar este passado, mas também como meio de buscar alternativas para a produção de insumos que tenham maior aceitação e vendas.

Quanto às formas de comercialização dos produtos gerados nas iniciativas, foram apontadas que estas ocorrem em feiras, eventos, lojas, venda na vizinhança, venda de 
forma ambulante, venda pela internet, venda na própria unidade onde é desenvolvida a iniciativa, contrato com empresa privada, venda para parceiros, supermercados, bazares, mesas de negociações, compra para revenda e consignação. A variedade de locais de venda e forma de comercialização revela um esforço em ampliar estes espaços e a consequente entrada destes produtos no circuito da comercialização.

Formas mais evoluídas de comercialização como, por exemplo, venda online pela internet, contrato com empresa privada, venda para parceiros, supermercados e mesas de negociações foram apontadas quase que em sua totalidade pelos serviços de geração de trabalho e renda, o que pode indicar um maior potencial destas iniciativas para se organizarem enquanto grupo produtivo se comparado às que se tratam de um único grupo de produção.

É importante ressaltar que esta perspectiva pode se sustentar no fato de que, embora todas as iniciativas estejam vinculadas a um serviço de saúde mental, as que se tratam de serviços de geração de trabalho e renda ocorrem, quase em sua totalidade, em espaço próprio, desvinculadas do serviço de saúde, ao contrário do que ocorre nas que se tratam de um único grupo de produção, que ocorrem dentro de CAPS e de Centros de Convivência. Sustenta-se que as iniciativas desenvolvidas fora dos serviços de saúde mental e, neste caso, se caracterizam como serviços de geração de trabalho e renda, possuem maiores oportunidades para organizar a produção, a dinâmica do trabalho e, consequentemente, melhores condições de estabelecerem parcerias, visto que se prestam exclusivamente a propor o trabalho e articular várias instâncias para que este se consolide. Como consequência, é possível que esta condição justifique o fato dos serviços de geração de trabalho e renda contarem com meios de comercialização mais diversificados e evoluídos se comparados aos meios das iniciativas que se tratam de um único grupo de produção.

Quanto à renda mensal gerada por participante, os resultados são preocupantes e indicam que gerar renda ainda é um dos maiores desafios destas iniciativas, visto que as retiradas, em sua maioria, são ainda muito baixas, evidenciando iniciativas que não conseguem gerar renda mensal aos usuários de forma que a partilha, em algumas delas, chega a ser feita a cada dois, três e até seis meses. Em termos de valores de renda por pessoa, esta variou bastante havendo iniciativa que gera uma renda mensal média por pessoa de $\mathrm{R} \$ 422,30$ até aquelas que vivenciam meses com renda zero.

Esta condição retrata uma situação alarmante e urgente frente à proposta que existe atualmente de gerar trabalho e renda, e cuja renda deve viabilizar a participação social dos usuários no mundo das trocas materiais. Nesta direção, Martins ${ }^{21}$ aponta que o trabalho remunerado apresenta-se como um divisor de águas na história entre a loucura e o trabalho, tendo na remuneração a moeda de troca no mundo real e concreto do trabalho em sociedade, intercambiando e possibilitando trocas subjetivas e relações sociais.

A dificuldade para gerar renda também foi mencionada em estudos que tratam de iniciativas de geração de trabalho e renda ${ }^{7}, 13,14,20$.

Nesse sentido, o estudo desenvolvido por Gigante ${ }^{20}$ revelou que, para grande parte das experiências de geração de trabalho e renda estudadas, o desafio principal é gerar renda satisfatória e ganhos maiores. Além deste, o estudo desenvolvido por Tagliaferro ${ }^{13}$ evidenciou que, para a equipe de incubação de um empreendimento solidário da saúde mental, a renda gerada pelo grupo ainda é insatisfatória o que leva ao questionamento sobre se o empreendimento é, de fato, um espaço de trabalho ou um espaço para ocupar o tempo. Ainda, Carvalhaes ${ }^{7}$ questiona se, frente à renda tão limitada gerada nas experiências investigadas em seu estudo, é possível vislumbrar uma real conquista de autonomia pelos sujeitos, bem como o exercício da autogestão e sobrevivência.

Esta condição evidenciada no presente estudo e nos estudos supracitados suscita a discussão acerca da necessidade de se desenvolverem mecanismos e estratégias que viabilizem a produção, bem como a comercialização dos produtos nestas iniciativas com vistas a gerar renda. Trata-se de uma condição fundamental para que a proposta de trabalho no contexto da saúde mental cumpra com a missão de, gerando renda, viabilizar o acesso dos usuários ao mundo das trocas materiais e sociais permitindo assim uma efetiva inclusão social.

O presente estudo revelou que as iniciativas investigadas estabelecem diversas parcerias, dentre elas, destacam-se a título de exemplo, Secretaria de Saúde, Secretaria do Trabalho e Renda, Fórum de Economia Solidária, Serviço Brasileiro de Apoio às Micro e Pequenas Empresas (SEBRAE), Serviço Nacional de Aprendizagem Comercial (SENAC), dentre outras mencionadas. Foram apontadas que as contribuições destas parcerias se dão, dentre outras, por meio de concessão de espaço físico, recurso material, orientações técnicas, ampliação de vendas, viabilização de recursos financeiros por meio de participação em editais e participação em eventos.

As parcerias revelam-se importantes meios de articulação do campo da saúde mental com outros espaços, o que viabiliza não só a concessão de recursos na tentativa 
de suprir demandas das iniciativas e auxilia-las em sua consolidação, mas permitem a ampliação do campo de trocas de saberes e de construção de uma nova imagem dos usuários da saúde mental como sujeitos produtores de valores com capacidade e potencial produtivo.

Carvalhaes ${ }^{7}$ defende o investimento em parcerias com outras instâncias que não só as relacionadas ao poder público. Para o autor, quanto mais as iniciativas necessitam de apoio de instâncias do governo, menos independentes e autônomas elas são. Defende, no entanto, não a ausência de apoio do poder público, mas que estas iniciativas estabeleçam parcerias outras com vistas a serem autônomas em seus projetos, a viabilizarem o protagonismo dos participantes, bem como se organizarem e se consolidarem a partir de suas próprias ações.

A vinculação à economia solidária foi apontada em nove das 10 iniciativas participantes do estudo, revelando que nestas tem-se buscado assumir o compromisso com uma nova perspectiva de trabalho e um envolvimento com as atuais políticas públicas de saúde mental e economia solidária.

Dentre as formas de vinculação à economia solidária, foi apontada que esta se dá por meio da forma com que o trabalho é desenvolvido, ou seja, pautado nos princípios desta economia, por meio do Fórum de Geração de Renda da cidade e por meio da Rede de Saúde Mental e Economia Solidária.

$\mathrm{Na}$ concepção de $\mathrm{Martins}^{21}$, a escolha pela economia solidária não é por acaso, já que, para a autora, os usuários da saúde mental, vistos como trabalhadores solidários, têm conseguido apoio tanto para seu acesso ao contexto social e comunitário quanto para decidirem e gerirem suas próprias vidas. Além disso, o princípio da autogestão representa um dos caminhos para lidar com a exclusão e com a ideia de que as pessoas com transtornos mentais são incapazes e, portanto, necessitam de tutela e proteção.

A economia solidária se caracteriza como uma resposta à exclusão promovida pelo mercado de trabalho, resposta esta organizada por aqueles que desejam uma sociedade que não seja regida pela competição e que produz continuamente vitoriosos e derrotados. A Reforma Psiquiátrica também é composta por aqueles que desejam uma sociedade sem manicômios e que, portanto, se unem às pessoas com transtorno mental em busca da construção de meios institucionais que viabilizem a inserção social e econômica destas pessoas ${ }^{22}$. É por meio deste ideal pela inclusão e por uma sociedade mais solidária que vem se estabelecendo possibilidades reais de proposição do trabalho às pessoas usuárias de serviços de saúde mental pela via da economia solidária. É nesse contexto que se evidencia a importância da articulação do Ministério da Saúde e do Ministério do Trabalho inspirados pela economia solidária ${ }^{23}$, com vistas a fomentar trabalhos inclusivos.

Segundo Pacheco ${ }^{24}$, a articulação com a economia solidária permite que os usuários vivenciem maiores possibilidades de inclusão social, visto que fazer parte da rede de economia solidária possibilita a participação em feiras, eventos, seminários e demais atividades relacionadas a esta. Considera ainda que se trata de uma experiência muito rica, uma vez que além da oferta de trabalho, possibilita que se realizem trocas de apoio e cuidado, onde, apesar de não haver a figura de um patrão, todos trabalham de maneira responsável, solidária e sem discriminação. Nesta perspectiva de trabalho "o maior capital é o social" $(\text { p. } 222)^{24}$.

\section{CONSIDERAÇÕES FINAIS}

A proposta de geração de trabalho e renda no âmbito da saúde mental tem sido reconhecida como um dos pilares fundamentais para a consolidação da inclusão social e do direito de cidadania dos usuários da saúde mental preconizados pelo movimento da Reforma Psiquiátrica. Destaca-se, entretanto, que enquanto proposta de um trabalho reconhecido socialmente e cindido da perspectiva terapêutica, esta é ainda uma prática bastante nova e que tem trazido como exigência um empenho constante dos profissionais que atuam nestas iniciativas e de instâncias políticas para que sejam construídas possibilidades reais e viáveis de trabalho para a população usuária da saúde mental.

Nesse sentido, o presente estudo revelou aspectos potenciais desta proposta para a afirmação dos usuários como cidadãos e potenciais trabalhadores, entretanto, evidenciou a necessidade de maiores investimentos com vistas a enfrentar desafios importantes tais como: a periodicidade do trabalho; a escolha e diversificação da atividade produtiva e a necessidade de investimento em prestação de serviços; o investimento em grupos mistos e, principalmente, a urgência de gerar renda.

Não há dúvidas de que a proposta de trabalho no âmbito da saúde mental é um importante dispositivo de reabilitação psicossocial e necessita de investimentos e inovações constantes para se tornar cada vez mais possível e consolidada. Nesse sentido, considera-se que novos estudos sejam desenvolvidos, principalmente, com vistas a traçar novas estratégias para lidar com as dificuldades e desafios encontrados nestas iniciativas. 


\section{REFERÊNCIAS}

1. Brasil. Ministério da Saúde. Secretaria de Atenção à Saúde. Reforma psiquiátrica e política de saúde mental no Brasil Documento apresentado à Conferência Regional de Reforma dos Serviços de Saúde Mental: 15 anos depois de Caracas. Brasília; 2005. Disponível em: http://bvsms.saude.gov.br/ bvs/publicacoes/Relatorio15_anos_Caracas.pdf.

2. Delgado PG. Conferência de abertura: Economia solidária e Saúde Mental. In: Brasil. Ministério da Saúde. Secretaria de Atenção à Saúde. Saúde mental e economia solidária: inclusão social pelo trabalho. Brasília; 2005. p.15-30.

3. Brasil. Ministério da Saúde. Secretaria de Atenção à Saúde. Saúde mental e economia solidária: inclusão social pelo trabalho. Balanço da política, análise da expansão da rede brasileira de saúde mental e economia solidária, e agenda para os próximos anos. Brasília; 2010.

4. Alcântara LC. Economia solidária e oficinas de trabalho na saúde mental. In: Merhy EE, Amaral H, organizadores. A reforma psiquiátrica no cotidiano II. São Paulo: Aderaldo \& Rothschild; 2007. p.151-81.

5. Martins RCA. Saúde mental e economia solidária: inclusão social pelo trabalho. Brasília: Ministério da Saúde, Secretaria de Atenção à Saúde; 2005. Disponível em: http://sites.poli. usp.br/p/augusto.neiva/nesol/Publicacoes/Anais\%20-\%20 Grava $\% \mathrm{C} 3 \% \mathrm{~A} 7 \% \mathrm{C} 3 \% \mathrm{~A} 3 \mathrm{o} /$ arquivos $\% 20 \mathrm{III} \% 20$ Encontro/ Tra-1.htm.

6. Saraceno B. Reabilitação psicossocial: uma estratégia para a passagem do milênio. In: Pitta AMF, organizadora. Reabilitação psicossocial no Brasil. 2a ed. São Paulo: Hucitec; 2001. p.13-8.

7. Carvalhaes AG. O lugar do trabalho solidário na reforma psiquiátrica brasileira [Dissertação]. Belo Horizonte: Faculdade de Filosofia e Ciências Humanas, Universidade Federal de Minas Gerais; 2008. Disponível em: http:// www.bibliotecadigital.ufmg.br/dspace/handle/1843/TMCB7WVKRP.

8. Andrade MC, Burali MAM, Vida A, Fransozio MBB, Santos RZ. Loucura e trabalho no encontro entre saúde mental e economia solidária. Psicol Ciênc Prof. 2013;33(1):174-91. http://dx.doi.org/10.1590/S1414-98932013000100014.

9. Brasil. Ministério da Saúde. Secretaria de Atenção à Saúde. Relatório final do grupo de trabalho saúde mental e economia solidária instituído pela portaria interministerial n 353, de 7 de março de 2005. Brasília; 2006.

10. Brasil. Ministério da Saúde. Secretaria de Atenção à Saúde. Saúde mental em dados - 2, 2(I). Brasília; 2006. Disponível em: file:///C:/Users/Administrador/Downloads/sm\%20 em\%20dados\%2002.pdf.

11. Brasil. Ministério da Saúde. Secretaria de Atenção à Saúde. Saúde mental em dados - 11, 11(VII). Brasília; 2012. Disponível em: file://C:/Users/Administrador/Downloads/ sm\%20em\%20dados\%2011.pdf.

12. Delgado PG. Reforma psiquiátrica e inclusão social pelo trabalho. In: Brasil. Ministério da Saúde. Secretaria de Atenção à Saúde. Saúde mental e economia solidária: inclusão social pelo trabalho. Brasília; 2005. p.9-10.

13. Tagliaferro P. Enfrentando desafios e construindo possibilidades: a experiência da equipe no processo de incubação de um empreendimento solidário formado por usuários de um CAPS [Dissertação]. São Carlos: Universidade Federal de São Carlos; 2011. Disponível em: http://www.bdtd.ufscar.br/htdocs/tedeSimplificado// tde_busca/arquivo.php? codArquivo $=4029$.

14. Milioni DB. A experiência de trabalho de usuários de um CAPS, integrantes de um empreendimento solidário: construindo vidas e possibilidades [Dissertação]. São Carlos: Universidade Federal de São Carlos; 2009. Disponível em: http://www.bdtd.ufscar.br/htdocs/tedeSimplificado/ tde_busca/arquivo.php?codArquivo=2983.

15. Singer P. Conferência de abertura: economia solidária e saúde mental. In: Brasil. Ministério da Saúde. Secretaria de Atenção à Saúde. Saúde mental e economia solidária: inclusão social pelo trabalho. Brasília; 2005. p.15-30.

16. Delgado PG. Proposta de criação da Rede Nacional de Saúde Mental e Economia Solidária. In: Brasil. Ministério da Saúde. Secretaria de Atenção à Saúde. Saúde mental e economia solidária: inclusão social pelo trabalho. Brasília; 2005. p.82-8.

17. Ghirardi MIG. Cooperativas de trabalho. In: Cavalcanti A, Galvão C, organizadoras. Terapia ocupacional: fundamentação e prática. Rio de Janeiro: Guanabara Koogan; 2007. p.291-2.

18. Saraceno B. Libertando identidades: da reabilitação psicossocial à cidadania possível. 2a ed. Rio de Janeiro: Te Corá/ Instituto Franco Basaglia; 2001.

19. Brasil. Decreto n. 8.163, de 20 de dezembro de 2013. Institui o Programa Nacional de Apoio ao Associativismo e Cooperativismo Social - Pronacoop Social, e dá outras providências. Brasília, DF: Presidência da República; 2013. Disponível em: http://www.planalto.gov.br/ccivil_03/_ Ato2011-2014/2013/Decreto/D8163.htm. 
20. Gigante MP. Perfil das oficinas de geração de trabalho e renda no âmbito da atenção psicossocial no Brasil [Dissertação]. Pelotas: Universidade Católica de Pelotas; 2011. Disponível em: http://biblioteca.ucpel.tche.br/tedesimplificado/tde busca/arquivo.php? $\operatorname{cod}$ Arquivo $=286$.

21. Martins RCA. Saúde mental e economia solidária: construção democrática e participativa de políticas públicas de inclusão social e econômica. In: Cortegoso AL, Lucas MG, organizadores. Psicologia e economia solidária: interfaces e perspectivas. São Paulo: Casa do Psicólogo; 2008. p.245-62.

22. Singer P. Saúde mental e economia solidária. In: Brasil.
Ministério da Saúde. Secretaria de Atenção à Saúde. Saúde mental e economia solidária: inclusão social pelo trabalho. Brasília; 2005. p.11-2.

23. Costa H. Apresentação. In: Brasil. Ministério da Saúde. Secretaria de Atenção à Saúde. Saúde mental e economia solidária: inclusão social pelo trabalho. Brasília; 2005. p.7-8.

24. Pacheco JL. Inclusão social através do trabalho. In: Cortegoso AL, Lucas MG, organizadores. Psicologia e economia solidária: interfaces e perspectivas. São Paulo: Casa do Psicólogo; 2008. p.219-24.

Artigo recebido em: 10.05.2015

Artigo aceito em: 15.08 .2015 